\title{
Genetic diversity and patterns of population structure in Creole goats from the Americas
}

C. Ginja*, L. T. Gama ${ }^{\dagger}$, A. Mart'ınez ${ }^{\ddagger}$, N. Sevane ${ }^{\$}$, I. Martin-Burriel ${ }^{\pi}$, M. R. Lanari**,

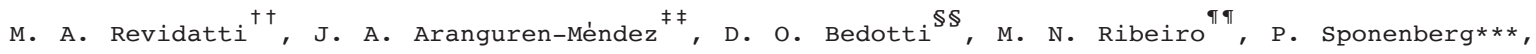

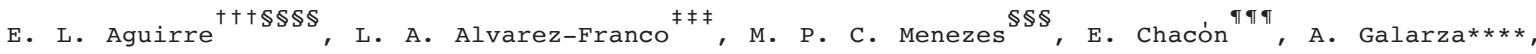

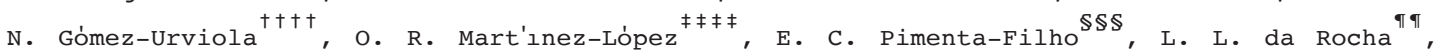

A. Stemmer****, V. Landi ${ }^{\ddagger}$ and J. V. Delgado-Bermejo ${ }^{\ddagger}$

*CIBIO-InBIO - Centro de Investigaǵao em Biodiversidade e Recursos Genèticos, Universidade do Porto, Campus Agrário de Vairao, Rua Padre Armando Quintas n. 7, 4485-661 Vairao, Portugal. †'CIISA, Faculdade de Medicina Veterinária, Universidade de Lisboa, Lisboa, Portugal. ${ }^{\ddagger}$ Departamento de Genética, Universidad de Córdoba, Campus de Excelencia Internacional Agroalimentario ceiA3, Córdoba,

Spain. \$Departamento de Producción Animal, Universidad Complutense de Madrid, Madrid, Spain. ${ }^{M}$ Martin-Burriel, Laboratorio de Genética Bioqu'ımica, Facultad de Veterinaria, Universidad de Zaragoza, Zaragoza, Spain. **Area de Producción Animal, Instituto Nacional de Tecnolog'ıa Agropecuaria EEA, Bariloche, Argentina.

† Facultad de Ciencias Veterinarias, Universidad Nacional del Nordeste, Corrientes,

Argentina. ${ }^{\ddagger \neq}$ Facultad de Ciencias Veterinarias, Universidad de Zulia, Maracaibo-Zulia, Venezuela. $\mathbb{S}_{\text {Instituto }}$ Nacional de Tecnolog'ıa

Agropecuaria EEA Anguil “Ing. Agr. Guillermo Covas", Bariloche, Argentina. "Departamento de Zootecnia, Universidade Federal Rural de Pernambuco, Recife, PE, Brazil. ***Virginia-Maryland Regional College of Veterinary Medicine, Virginia Tech, Blacksburg, VA, USA.

†† Universidad Nacional de Loja, Loja, Ecuador. ${ }^{\prime \neq}$ Universidad Nacional de Colombia, Sede Palmira, Colombia. $\$ \$ \$$ Universidade Federal da

Para'ıba, Areia, PB, Brazil. "ศा Universidad Técnica de Cotopaxi, La Maná, Ecuador. ****Universidad Mayor de San Simón, Cochabamba, Bolivia. ${ }^{\dagger \dagger}$ Universidad Nacional Micaela Bastidas de Apur'ımac, Abancay, Perú.

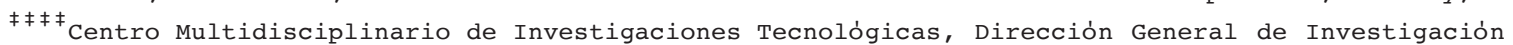
Cient'ıfica y Tecnológica, Universidad Nacional de Asunción, San Lorenzo, Paraguay.

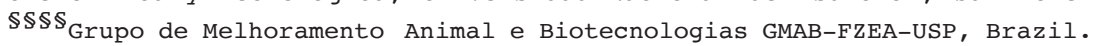

\begin{abstract}
Biodiversity studies are more efficient when large numbers of breeds belonging to several countries are involved, as they allow for an in-depth analysis of the within- and between-breed components of genetic diversity. A set of 21 microsatelites was used to investigate the genetic composition of 24 Creole microsatellites was used to investigate the genetic composition of 24 Creole
goat breeds ( 910 animals) from 10 countries to estimate levels of genetic variability, infer population structure and understand genetic relationships among populations across the American continent. Three commercial transboundary breeds were included in the analyses to investigate admixture with Creole goats. Overall, the genetic diversity of Creole populations (mean number of alleles $=5.82 \pm 1.14$, observed heterozygosity $=0.585 \pm 0.074$ ) number of alleles $=5.82 \pm 1.14$, observed heterozygosity $=0.585 \pm 0.074)$
was moderate and slightly lower than what was detected in other studies with breeds from other regions. The Bayesian clustering analysis without prior information on source populations identified 22 breed clusters. Three groups comprised more than one population, namely from Brazil (Azul and Grauna; Moxoto and Repartida) and Argentina (Long and shorthair Chilluda, Pampeana Colorada and Angora-type goat). Substructure was found in Criolla Paraguaya. When prior information on sample origin was considered, $92 \%$ of the individuals were assigned to the source population (threshold q $\geq 0.700$ ). Creole breeds are well-differentiated entities (mean coefficient of genetic differentiation $=0.111 \pm 0.048$, with the exception of isolated island populations). Dilution from admixture with commercial transboundary breeds populations). Dilution from admixture with commercial transboundary breeds
appears to be negligible. Significant levels of inbreeding were detected (inbreeding coefficient $>0$ in most Creole goat populations, $\mathrm{P}<0.05$ ). Our results provide a broad perspective on the extant genetic diversity of Creole goats, however further studies are needed to understand whether the observed geographical patterns of population structure may reflect the mode of goat colonization in the Americas.
\end{abstract}

Keywords admixture, biodiversity, domestic goats, genetic structure, short tandem repeats

E-mail: catarinaginja@cibio.up.pt

Accepted for publication 02 November 2016 


\section{Introduction}

Goats arrived in America during the second Columbus trip in 1493 (Rodero et al. 1992). Due to the adaptability of this species, they were promptly spread throughout the entire continent and easily integrated into the farming activities of native civilizations, which until then were rearing mostly South American camelids. Natives and colonizers jointly contributed to the spread of goats throughout the continent, and there are now approximately 36 million goats in Latin America and the Caribbean and about 3 million in North America, representing about $3.5 \%$ of the world census (FAO 2007). Over time, several new goat populations were established in very distinct ecosystems on the American continents. This probably represented the major evolution- ary event for the species subsequent to their domestication in the Middle East, approximately 10 000 years ago (Naderi et al. 2008). Goats in the Americas belong to mostly native breeds broadly called Creole, presumably with origins in the Iberian goats that arrived in the continent since the 15th century, during the period of European conquest and colonization (Rodero et al. 1992 )

In spite of the social and economic relevance of American goats, these animals are poorly characterized. According to FAO, there are only about 28 breeds recognized in the region (Boettcher et al. 2014). The vast majority of native American goats are referred to as Creole, a reservoir of genetic diversity that has not been characterized. Creole goats are important resources available for endogenous rural development, especially in marginal areas and under a climatic change scenario, but they may be threatened by crossbreeding with and/or replacement by commercial transboundary breeds.

Molecular biology provides tools for the study of within- and between-population genetic diversity. As with other livestock species, short tandem repeats (i.e. microsatellites) have thus far been the markers of choice for genetic diversity studies (Groeneveld et al. 2010; Lenstra et al. 2012). Several results concerning the survey of goat genetic diversity based on microsatellites have been published, including those surveying breeds from Asia ( $\mathrm{Li}$ et al. 2002; Fatima et al. 2008; Agaoglu \& Ertugrul 2012; Sulabda et al. 2012), Europe (Iamartino et al. 2005; Serrano et al. 2009; Bruno-de-Sousa et al. 2011; Martinez et al. 2015) and Africa (Traor'e et al. 2009; Missohou et al. 2011), and also breeds from Latin American countries such as Brazil (Menezes et al. 2006), Colombia (Calvo et al. 2012) and Cuba (Chacón et al. 2012). The recent development of a SNP array for goats (Tosser-Klopp et al. 2014) will probably lead to the replacement of microsatellites by these markers in the future, as discussed in a comprehensive review of genetic diversity studies in goats (Ajmone-Marsan et al. 2014). The use of SNP arrays and genome-wide next- generation sequencing methodologies are becoming more common. Nonetheless, microsatellites seem to be adequate for estimating genetic diversity and depicting breed relationships (Bruford et al. 2015), and more so when a large number of animals and populations are genotyped to allow for more comprehensive inferences regarding their genetic composition.

Few studies with microsatellites concerning the genetic relationship among goat breeds from more than one country and across different climatic regions have been published thus far (Oliveira et al. 2010; Ribeiro et al. 2012). Nevertheless, biodiversity studies are more efficient when a large number of breeds belonging to several countries is involved, as this allows for an indepth analysis of the within- and between-breed components of genetic diversity and inference on phylogenetic relationships. One example is the study by Canon et al. (2006), who carried out a broad microsatellite-based analysis of European and Middle East- ern goat breeds within the ECONOGENE consortium and detected an East-West cline in genetic diversity along the Mediterranean.

This study was carried-out in the framework of the CONBIAND

Network

(http://www.uco.es/conbiand/Bienve nida.html), which is an international scientific association dedicated to the characterization and conservation of zoogenetic resources from Iberoamerica. Within this net- work, several studies have been conducted to assess the genetic diversity of farm animals of the American continent, including cattle (Ginja et al. 2010, 2013; Delgado et al. 2012) and pigs (Revidatti et al. 2014). In the context of the Biogoat Consortium (http://biogoat.jimdo.com/), we designed a sampling strategy to capture historical signa- tures of goat introductions into the Americas, including populations from the Caribbean Islands (Cuba), which represents the point of arrival of European settlers in the 15th century and North America (United States) as well as South America (Colombia, Venezuela, Ecuador, Peru, Bolivia, Brazil, Paraguay, Argentina), following the routes of goat dissemination throughout the Americas (Primo 1992; Rodero et al. 1992; Villalobos Cort'es et al. 2011). As a first approach, we used microsatellites to investigate the genetic composition of 24 goat breeds from 10 American countries, with the aims to: (i) characterize their levels of genetic variability and population structure and (ii) under- stand the patterns of genetic relationships among goat populations across the American continent.

Material and methods

Sampling and DNA extraction

Blood or hair samples were collected from a total of 910 animals of 24 Creole goat populations from the Americas (breed acronym, sample size): Argentina - Angora-type goat (TAN, 14), Chilluda longhair ( $\mathrm{CHL}, 12$ ), Chilluda shorthair ( $\mathrm{CHC}, 11)$ Criolla del Nordeste (NEA, 39), Neuquina (NUQ, 50) and Pampeana Colorada (PCA, 14); 
Figure 1 Contour graphics of geographical coordinates of Creole goat populations in relation to the estimated (a) $\mathrm{He}$ and (b) Fis

values. Green areas correspond to the lower $\mathrm{He}$ and $\mathrm{Fis}$ values; pink areas correspond to the higher $\mathrm{He}$ and $\mathrm{Fis}$ values.

Abbreviation of breed names and sample sizes are as follows: Argentina - Angora-type Goat (TAN, 14), Chilluda longhair (CHL, 12), Chilluda shorthair (CHC, 11), Criolla del Nordeste (NEA, 39), Neuquina (NUQ, 50), and Pampeana Color-

ada (PCA, 14); Bolivia - Criolla Boliviana (BOL, 40); Brazil Canindé (CND, 40), Graúna (GRN $40)$, Marota (MRT, 40), Moxotó (MOX,

$40)$, Repartida (REP, 40), Azul (SAZ, 40) and undefined creole (SRD, 36); Colombia - Cri- olla Colombiana (COL, 24); Cuba Criolla Cubana (CUB, 40); Ecuador - Criolla del

Ecuador (ECU, 11) and Galapagos Goat (GAG, 23); Paraguay -

Criolla Paraguaya (PGY, 84); Peru - Criolla Peruana (PER, 61); United States of America -

Myotonic Goat (MYO, 43), San

Clemente Goat (SCL, 58), and

Spanish Goat (SPA, 64); Venezuela

- Criolla Venezolana (VEN, 46).

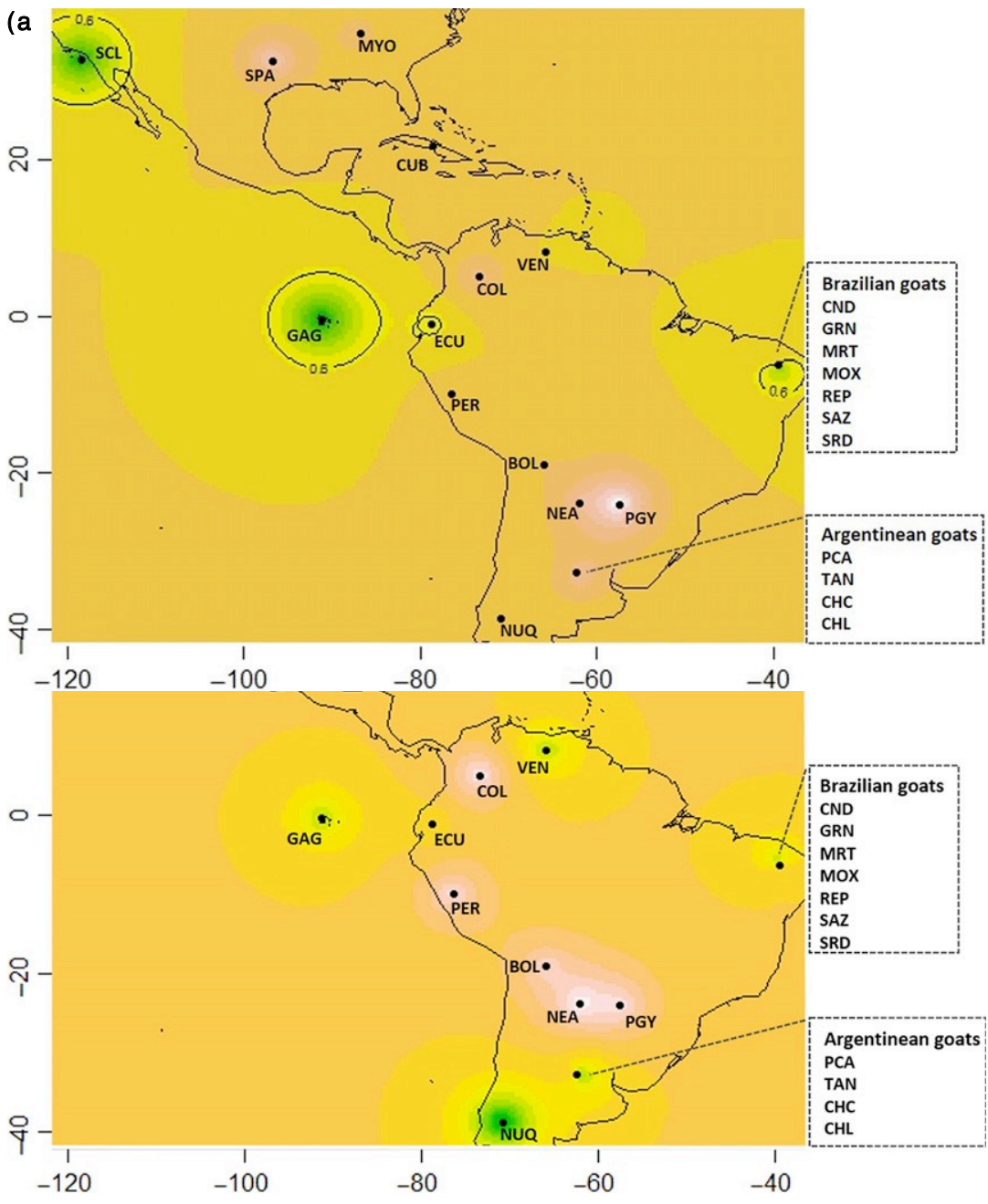

Bolivia - Criolla Boliviana (BOL, 40): Brazil Canind'e (CND, 40), Grauna (GRN, 40), Marota (MRT, 40 ), Moxotó (MOX, 40), Repartida (REP, 40), Azul (SAZ, 40) and undefined Creole (SRD, 36); Colombia - Criolla Colombiana (COL, 24); Cuba - Criolla Cubana (CUB, 40); Ecuador - Criolla del Ecuador (ECU, 11) and Galapagos Goat (GAG, 23); Paraguay - Criolla Paraguaya (PGY, 84); Peru - Criolla Peruana (PER, 61); United States of America Myotonic Goat (MYO, 43), San Clemente Goat (SCL, 58) and Spanish Goat (SPA, 64). Venezuela _ Criolla Venezolana (VEN, 46). Geographic locations of each population are shown in Fig. 1. Most of these populations are local breeds raised by small farmers, sometimes in family herds used for home con- sumption; but many are partially feral indistinct popula- tions living free, as is the case of isolated GAG and SCL goat populations from Galapagos and San Clemente Islands respectively. The SRD is a poorly defined population of goats from Brazil resulting from admixture among several local breeds, possibly with influence from exotic germplasm. Samples were also collected from 112 animals of three commercial transboundary goat breeds, with samples collected in Brazil - Alpine (ALP, 35) and Anglo-Nubian (ANG, 41), and Spain - Saanen (SAAN, 36), to investigate admixture with local Creole goats. To minimize the degree of relationship among individuals, unrelated animals were selected whenever possible. For a broad representation of the genetic variability, samples were collected from several herds per breed. Biological samples were collected by qualified veterinarians during their routine practice in the framework of official health control programs. Therefore, no official health control programs. Therefore, no biological material. Genomic DNA was extracted from whole blood or 
hair roots following the methodology described by Walsh

et al. (1991).

STR genotyping

We analyzed a set of 21 short tandem repeat (STR) markers, selected following the recommendations of the ISAG-FAO Advisory Group on Farm Animal Genetic Diversity for studies in goats (Hoffmann et al. 2004; Hoffmann 2010), as follows: BM1329, BM6506, BM6526, BM8125, CRSM60， CSRD247， ЕTH010， ЕTH225， HAUT27, ILSTS011， INRA063， MAF065， MAF209, MCM527, MM12, OarFCB011， OarFCB048， OarFCB304， SPS115, SRCRSP08,

and TGLA122. STR markers were amplified in multiplex polymerase chain reactions (PCRs) using fluorescence- labeled primers as described by Bruno-de-Sousa et al. (2011). PCR fragments were separated by capillary elec- trophoresis on ABI $377 \mathrm{XL}$ instruments (Applied Biosystems), according to the manufacturer's recommendations. Allele sizes were determined using the internal size standard

GeneScan-400HD ROX (Applied Biosystems), and genotypes were called using GENOTYPER ${ }^{\circledR} 2.5 .1$ software. Reference samples were included in each run for consistency of allele assignments.

\section{Statistical analyses}

Allele frequencies, effective number of alleles $(\mathrm{ne})$ and number of population-specific alleles (private alleles, PA) were determined with GENALEX v. 6.5 (Peakall \& Smouse 2006) for each locus and breed. The frequency of null alleles ( $r$ ) per locus within each breed was estimated with FREENA Software (available at http://wwwl.montpellier.inra. fr/URLB/; Chapuis Estoup 2007) following Dempster et al. (1977). Deviations from Hardy-Weinberg equilibrium (HWE) were assessed with GENEPOP v. 4 software (Raymond \& Rousset 2003). Both global tests across populations and loci and tests per locus per population were carried out using the method of Guo \& Thompson (1992), and the P- values were obtained using a Markov chain of 10000 dememorization steps, 500 batches and 5000 iterations. Genotypic linkage disequilibrium (LD) was also calculated using this software and the same Markov chain settings. FSTAT v. 2.9.3 (Goudet 2001) was used to estimate the F statistics per locus according to Weir \& Cockerham (1984), and P-values were obtained based on 1000 randomizations. Allelic richness (Rt) over all loci for each breed was also calculated using this software, assuming a minimum of three animals per breed.

The software GENETIX v. 4.05 (Belkhir et al. 1996-2004) was used to estimate observed ( $\left.\mathrm{H}_{\mathrm{O}}\right)$ and unbiased within- breed expected ( $\mathrm{He}_{\mathrm{e}}$ heterozygosities and mean number of alleles per breed (MNA) and to calculate the inbreeding coefficient (Fis) in each breed, with P-values obtained based on 1000 permutations. The 'plot.membership' function
(Olivier Franjois; http://membrestimc.imag.fr/Olivier.Fra ncois/index.html) was used in $\mathrm{R}$ software v. 3.2.4 (1999-2016, R Foundation for statistical Computing) to obtain contour graphics of geographical coordinates in relation to $\mathrm{He}$ and $\mathrm{F}$ is values estimated for each Creole goat population. A principal components analysis was carried out in PCAGEN v. 1.2 (available at http://www2.unil.ch/popgen/ softwares/pcagen.htm; Goudet 1999) to represent breed relationships based on allele frequencies, assuming P-values for the axes obtained from 1000 randomizations of geno- types. Population pairwise DA distances of Nei et al.

(1983) were calculated in POPULATIONS (Langella 1999-2002) and used to obtain a network of breed relationships following the Neighbor-Net method in Bryant 2006). SPLITSTREE 4 v. 4.13 (Huson \&

Genetic structure and the degree of admixture of creole native goats were investigated using the Bayesian clustering procedure of STRUCTURE V. 2.3.4 (Pritchard et al. 2000). The most probable number of ancestral populations (K) given the observed genotypic data was estimated by performing six independent runs for each $\mathrm{K}(1<\mathrm{K}<30)$ with burn-in lengths and Markov chain Monte Carlo (MCMC) iterations of 50000 and 300000 respectively. The alpha (degree of admixture) parameter was inferred from the data using the default settings and an admixture model with correlated allele frequencies (Falush et al. 2003). Assessment of the change in the log of the likelihood function and the method of Evanno et al. (2005) were used to identify the most probable $\mathrm{K}$ by determining the modal distribution of $\Delta \mathrm{K}$. The STRUCTURE analysis was repeated for some subsets of the data to assess within-breed substructure. Assignment tests were performed with STRUCTURE using prior information of source breeds and the settings described above for the MCMC. The proportion of each individual genotype in each cluster or breed (q) and the probability of ancestry in other breeds were estimated. The percentage of individuals assigned to source breeds was calculated for distinct threshold q values.

Results

Molecular markers

Among the 21 markers, there was no evidence for null alleles at important frequencies $(r>0.2)$ across various breeds, and a total of 236 alleles were detected at all loci across the various goat populations. Measures of genetic variability as well as F-statistics for each STR are shown in Table S1. The total number of alleles per locus ranged from 3 for MAF209 to 21 for OarFCB304, and the mean number of alleles per locus ranged from 2.22 for MAF209 to 9.52 for BM6506. The effective number of alleles, i.e. the number of alleles that if equally frequent would result in the observed homozygosity, was about four for most loci (BM1329, CRSM60, CSRD247, OarFCB011, OarFCB048, 
OarFCB304, SRCRSP08 and TGLA122), and ranged from one for MAF209 to five for BM6526, MAF065 and MM12. Allelic richness per locus, i.e. the number of different alleles independent of sample size, was also about four for most loci (BM1329, BM6506, BM8125， CRSM60， CSRD247， ILSTS011, MAF065, MCM527, OarFCB011, OarFCB048,

OarFCB304, SRCRSP08 and TGLA122) and ranged from two for ETH225, MAF209 and SPS115 to five for BM6526 and MM12. Private alleles (i.e., an allele at a given locus found exclusively in one population) were detected in 10 of the 21 loci studied; however, only for ETH225, MAF065 and MM12 were these private alleles detected in frequen- cies $\geq 0.05$. The highest heterozygosity was found for MM12 $\left(\mathrm{H}_{\mathrm{O}}=0.760\right.$ and $\mathrm{He}=$ $0.768)$ and BM6526

$\left(\mathrm{H}_{\mathrm{O}}=0.746\right.$ and $\left.\mathrm{H}_{\mathrm{e}}=0.793\right)$ and the lowest for MAF 209

$\left(\mathrm{H}_{\mathrm{O}}=0.224\right.$ and $\left.\mathrm{H}_{\mathrm{e}}=0.244\right)$ and $\mathrm{ETH} 225\left(\mathrm{H}_{\mathrm{O}}=\right.$ 0.273 and

$\left.\mathrm{H}_{\mathrm{e}}=0.319\right)$. The $\mathrm{F}$ is value per locus had an overall mean of

$0.083 \pm 0.058$ and ranged from -0.012 for BM8125 to

0.204 for SPS115. Fit and Fst per locus had overall means of

$0.211 \pm 0.058$ and $0.134 \pm 0.033$ respectively. Out of the

21 STRs analyzed in each breed, BM6506, MAF065, SPS115 and SRCRSP08 showed significant $(P<0.05)$ HWE deviations across 10 or more breeds. The LD was significant $(P<0.0001)$ for 20 STR pairs; however, only the following three pairs appear to correspond to loci located in the same chromosome: BM1329/SRCRSP08, BM8125/MAF209 and BM8125/OarFCB0 48 .

\section{Genetic diversity within populations}

Estimates of within-breed genetic diversity are summarized in Table 1 and in the contour graphics shown in Fig. 1. Overall, the genetic diversity of the 24 Creole goat popu- lations analyzed here (MNA $=5.82 \pm 1.14, \mathrm{ne}=3.30 \pm$ $0.67, \mathrm{Rt}_{t}=3.01 \pm 0.36, \quad \mathrm{H}_{\mathrm{O}}=0.585 \pm 0.074$ and $\mathrm{H}_{\mathrm{e}}=$

$0.638 \pm 0.079$ ) was moderate and slightly lower than that

detected with a similar panel of STRs in their European counterparts (see Canon et al. 2006; Bruno-de-Sousa et al. 2011). Isolated Creole goat populations from Galapagos and San Clemente Islands had the lowest diversity with respec- tively 3.05 \pm 1.24 and $4.14 \pm 1.39$ for MNA, $1.98 \pm 0.69$

and $2.10 \pm 0.89$ for $n_{e}, 2.12 \pm 0.64$ and $2.24 \pm$ 0.65 for

Rt, $0.411 \pm 0.258$ and $0.389 \pm 0.183$ for $\mathrm{H}_{\mathrm{O}}$, and

$0.433 \pm 0.243$ and $0.452 \pm 0.208$ for $\mathrm{He}$ (green areas in Fig. 1a). The highest genetic diversity was found in PGY from Paraguay and SPA from North America with respec- tively $8.71 \pm 3.32$ and 7.81 \pm 2.98 for MNA, $5.19 \pm 2.02$ and $4.24 \pm 1.71$ for $\mathrm{n}_{\mathrm{e}}, 3.73 \pm 0.68$ and $3.43 \pm 0.77$ for $\mathrm{Rt}_{\mathrm{t}} 0.677 \pm$ 0.132 and $0.678 \pm 0.168$ for $\mathrm{H}_{\mathrm{O}}$, and $0.777 \pm$ 0.101 and $0.717 \pm 0.153$ for $\mathrm{He}_{\mathrm{e}}$ respectively (pink areas in Fig. 1a). Despite their low sample size, the Argentinean longhair goat populations $\mathrm{TAN}$ and $\mathrm{CHL}$ had high genetic diversity: $\mathrm{H}_{\mathrm{O}}=$ $0.668 \pm 0.173$ and $\mathrm{H}_{\mathrm{O}}=0.669 \pm 0.160$, and $\mathrm{H}_{e}=$ $0.711 \pm 0.124$ and $\mathrm{H}_{e}=0.720$

\pm 0.130 respectively. Also, the crossbred SRD goat population from Brazil showed high genetic diversity $\left(\right.$ MNA $=6.33 \pm 2.83, \mathrm{n}_{\mathrm{e}}=3.87 \pm 1.47$, $R_{t}=3.28 \pm 0.79$,

$\mathrm{H}_{\mathrm{O}}=0.640 \pm 0.182$ and $\left.\mathrm{He}_{\mathrm{e}}=0.697 \pm 0.178\right)$. Among the three commercial transboundary breeds analyzed, ALP had the highest diversity (MNA $=6.76 \pm 2.72$, $\mathrm{n}_{\mathrm{e}}=4.08 \pm 1.65, \mathrm{Rt}=3.37 \pm 0.83, \mathrm{H}_{\mathrm{O}}=$ $0.674 \pm 0.205$ and $\mathrm{He}_{\mathrm{e}}=$

$0.701 \pm 0.198)$. Overall, the genetic diversity estimates for this breed group were similar to those observed for Creole goats (MNA = $6.43 \pm 0.50, \quad \mathrm{n}_{\mathrm{e}}=3.55 \pm 0.53$,

$R_{t}=3.15 \pm 0.22, \quad \mathrm{H}_{\mathrm{O}}=0.634 \pm 0.036$

$\mathrm{H}_{\mathrm{e}}=$

$0.664 \pm 0.033)$. Private alleles were detected in 14 breeds (Argentinean CHC and NUQ; Brazilian GRN, MRT, MOX and SAZ; Ecuadorian ECU and GAG; Paraguayan PGY; Peruvian PER; North American MYO; Venezolana VEN; and transboundary ALP and SAAN); however, only three out of 17 PAs were detected in frequencies $\geq 0.05$ (one each in MYO, ECU and $\mathrm{CHC})$. The number of loci that had a significant heterozygote deficit $(P<0.05)$ ranged from 0 (PCA) to 14 (PGY). The HWE deviations detected are most probably due to inbreeding, as the withinbreed Fis esti- mates were significantly $(P<$ 0.05 ) higher than zero in all populations, except in Argentinean TAN, NUQ and PCA; Brazilian GRN; and Galapagos Goat (depicted in green in Fig. 1b). For 13 Creole goat populations, the $\mathrm{F}_{\text {is }}>0$ was highly significant $(P<0.001)$. Heterozygote excess was not significant for any of the locus/breed combinations tested.

\section{Genetic relationship among populations}

Pairwise population $F_{\text {St }}$ values, as shown in Table S2, were mostly significant for $P<0.05$. The lowest Fst values were found among Argentinean goat populations (overall mean of $0.041 \pm 0.025$; Table S3), particularly between $\mathrm{CHL}$ and $\mathrm{CHC}$ ($0.008), \operatorname{PCA}(0.017)$ and TAN $(0.020), \mathrm{CHC}$ and

TAN $(0.021)$ and PCA and TAN $(0.027)$, which were not significantly differentiated $(P<0.05)$. In spite of being significant, Fst values among Brazilian breeds were also low $(0.079 \pm 0.022)$, namely of MOX with CND (0.038) and REP (0.046), SAZ with GRN $(0.040)$ and CND with REP $(0.050)$. The highest Fst value was observed between Creole goat populations from Galapagos and San Clemente Islands $(0.391)$. The overall Fst value among the 24 Creole and three commercial transboundary breeds was

$0.134 \pm 0.071$ (Table S3). The lowest Fst values between Creole and commercial transboundary goats were found for SPA/SAAN (0.054) and SPA/ALP $(0.055)$, whereas the highest was observed for GAG/ANG $(0.299)$.

Breed relationships based on allele frequencies are depicted in the principal components analysis graph in Fig. 2. The island breeds GAG and SCL were the most distant, together with BOL and the commercial Anglo- Nubian goats. Based on axes 1 and 2, Brazilian breeds clustered together (shaded area in gray) and split from all other goat populations, which had a more central position. The Argentinean breeds also grouped together such that, 
Table 1 Mean number of alleles (MNA), effective number of alleles (ne), allelic richness (Rt), number of private alleles (PA), observed (Ho) and expected (He) heterozygosities, inbreeding coefficient (Fis), number of loci showing heterozygote deficit (HWEd) estimated with 21 STRs in 24 creole and three commercial transboundary goat breeds.

\begin{tabular}{|c|c|c|c|c|c|c|c|c|c|c|c|}
\hline Country & Breed & Abr. & $\mathrm{n}$ & MNA \pm SD & $\mathrm{ne} \pm \mathrm{SD}$ & $\mathrm{Rt} \pm \mathrm{SD}$ & PA & Ho $\pm \mathrm{SD}$ & $\mathrm{He} \pm \mathrm{SD}$ & $F_{\text {is }}$ & HWE \\
\hline \multicolumn{12}{|l|}{ Creole } \\
\hline Argentina & Angora & TAN & 14 & $5.62 \pm$ & $3.74 \pm$ & $3.28 \pm$ & & $0.668 \pm$ & $0.711 \pm$ & 0.062 & 2 \\
\hline Argentina & Chilluda longhair & $\mathrm{CHL}$ & 12 & $5.5 \hat{5} \pm$ & $3.7 \hat{\sigma} \pm$ & $3 . \hat{4} \hat{0} \pm$ & & $0.673 \pm$ & $\hat{0} .72 \hat{0} 0 \pm$ & $0.073 *$ & 2 \\
\hline Argentina & Cr. del Nordeste & NEA & 39 & $\overline{6} . \overline{4} \overline{3} \pm$ & $3 . \overline{7} \overline{7} \pm$ & $\hat{3} . \hat{2} \overline{4} \pm$ & & $0 . \overline{59} \overline{6} \pm$ & $\hat{0} . \overline{6} \overline{9} 0 \pm$ & $0.138 * * *$ & 9 \\
\hline Argentina & Neuquina & NUQ & 50 & $6.7 \hat{6} \pm$ & $\hat{3} . \hat{3} 2 \pm$ & $\hat{3} .019 \pm$ & 1 & $0 . \hat{6} \hat{3} \pm$ & $0.6 \overline{6} 48 \pm$ & 0.008 & 5 \\
\hline Argentina & Pampeana & PCA & 14 & $\overline{4} .8 \hat{6} \pm$ & $\hat{3} . \hat{2} \overline{8} \pm$ & $\hat{3} . \overline{0} \hat{9} \pm$ & & $0 . \overline{4} \overline{3} \pm$ & $\hat{0} . \overline{6} \hat{\overline{4}} \overline{4} \pm$ & 0.032 & 0 \\
\hline Bolivia & Ĉr. Boliviana & BOL & 40 & $5 . \hat{2} \overline{4} \pm$ & $\hat{3} . \hat{2} \hat{1} \pm$ & $\hat{2} . \overline{9} \hat{7} \pm$ & & $0.597 \overline{0} \pm$ & $0 \hat{0} \overline{6} \overline{8} \pm$ & $0.121 * * *$ & 9 \\
\hline Brazil & Canindè & $\mathrm{CND}$ & 40 & $\overline{5} . \overline{5} 2 \pm$ & 3.î̀ \pm & $\overline{2} . \overline{9} \overline{4} \pm$ & & $\overline{0} . \overline{8} \overline{9} \pm$ & $\overline{0} . \bar{\sigma} \overline{3} \dot{4} \pm$ & $0.071 * * *$ & 3 \\
\hline Brazil & Marota & MRT & 40 & $5 . \hat{2} \hat{4} \pm$ & $2.75 \pm$ & $\hat{2} . \overline{7} \hat{3} \pm$ & 1 & $\hat{0} . \overline{5} 5 \overline{5} \pm$ & $\hat{0} . \overline{5} 9 \overline{0} \pm$ & $0.061 * *$ & 6 \\
\hline Brazil & Moxotó & MOx & 40 & $\overline{5} . \overline{5} \overline{2} \pm$ & $\overline{2} . \overline{9} \overline{3} \pm$ & $\overline{2} . \overline{79} \pm$ & 1 & $\overline{0} . \overline{5} \overline{2} \overline{4} \pm$ & $\overline{0} . \overline{6} \overline{0} \overline{4} \pm$ & $0.133 * * *$ & 6 \\
\hline Brazil & Repartida & REP & 40 & $6.14 \pm$ & 3. $1 \hat{0} \pm$ & $\hat{2} . \overline{9} \overline{7} \pm$ & & $\hat{0} .589 \pm$ & $\hat{0} . \bar{\sigma} 3 \hat{z} \pm$ & $0.068 * * *$ & 3 \\
\hline Brazil & Azul & $\mathrm{SAZ}$ & 40 & $\overline{5} . \overline{5} \overline{2} \pm$ & $\overline{2} . \overline{6} \overline{1} \pm$ & $\hat{2} . \overline{6} \hat{1} \pm$ & 1 & $0 . \overline{1} \overline{7} \pm$ & $\overline{0} . \overline{5} \overline{4} \overline{7} \pm$ & $0.056 * *$ & 2 \\
\hline Brazil & Undefined Creole & SRD & 36 & $\overline{6} . \overline{3} \overline{3} \pm$ & $\overline{3} . \overline{8} \overline{7} \pm$ & $\overline{3} . \overline{2} \overline{8} \pm$ & & $0 . \overline{4} \overline{0} \pm$ & $0 . \overline{69} \overline{7} \pm$ & $0.082 * * *$ & 6 \\
\hline Colombia & Cr. Colombiana & COL & 24 & $\overline{5} . \overline{9} \overline{0} \pm$ & $\overline{3} . \dot{6} \overline{3} \pm$ & $\overline{3} . \overline{2} \overline{4} \pm$ & & $0 . \overline{9} \overline{2} \pm$ & $0 . \overline{6} \overline{8} \overline{0} \pm$ & $0.132 * * *$ & 6 \\
\hline Cuba & Cr. Cubana & CUB & 40 & 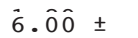 & $\overline{3} . \overline{0} \pm$ & $\hat{2} . \overline{9} \hat{2} \pm$ & & $\hat{0} . \overline{5} \overline{7} \overline{4} \pm$ & $\hat{0} . \overline{6} 2 \overline{9} \pm$ & $0.088 * * *$ & 5 \\
\hline Ecuador & Cr. Del Ecuador & $\mathrm{ECU}$ & 11 & $4.57 \pm$ & $2.79 \pm$ & $\hat{2} . \overline{8} \overline{4} \pm$ & 1 & $\hat{0} . \overline{5} \overline{2} \pm$ & $\hat{0} . \overline{5} \overline{8} \overline{7} \pm$ & $0.081 *$ & 3 \\
\hline Ecuador & Galapagos goat & GAG & 23 & $3.05 \pm$ & $1.98 \pm \pm$ & $\hat{2} . \hat{1} \hat{2} \pm$ & 1 & 0ิ. $4 \hat{1} \hat{1} \pm$ & $0 . \overline{4} 3 \hat{3} \pm$ & 0.053 & 3 \\
\hline Paraguay & Cr. Paraguaya & PGY & 84 & $8.7 i \pm$ & 5. $1 \hat{9} \pm$ & $\hat{3} . \overline{3} \pm$ & 3 & $0.6 \overline{7} \overline{7} \pm$ & $0 . .777 \pm$ & $0.130 * * *$ & 14 \\
\hline USA & Myotonic goat & мYо & 43 & $6 . \overline{3} \hat{3} \pm$ & $\overline{3} . \overline{3} \overline{1} \pm$ & $\hat{3} . \hat{0} \bar{\sigma} \pm$ & 1 & $\hat{0} .5 \overline{8} 0 \pm \pm$ & $\hat{0} . \bar{\sigma} \hat{\overline{1}} \hat{1} \pm$ & $0.124 * * *$ & 7 \\
\hline USA & San Clemente & $\mathrm{SCL}$ & 58 & $\overline{4} .1 \hat{4} \pm$ & 2. $1 \hat{0} \pm$ & $\hat{2} . \overline{2} \overline{4} \pm$ & & $0 . \overline{3} \overline{8} \overline{9} \pm$ & $\hat{0} . \overline{4} 5 \hat{2} \pm$ & $0.139 * * *$ & 4 \\
\hline USA & Spanish goat & $\mathrm{SPA}$ & 64 & $\overline{7} . \overline{8} \overline{1} \pm$ & $\overline{4} . \overline{2} \overline{4} \pm$ & $\overline{3} . \overline{4} \overline{3} \pm$ & & $0 . \bar{\gamma} \overline{8} \pm$ & 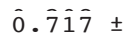 & $0.056 * * *$ & 6 \\
\hline Venezuela & Cr. Venezolana & VEN & 46 & $5 . \overline{3} 8 \pm$ & $\overline{3} . \overline{1} \overline{5} \pm$ & $\overline{2} . \overline{9} \overline{3} \pm$ & 1 & $0 . \overline{9} \overline{1} \pm$ & $0 . \overline{6} \overline{2} \overline{3} \pm$ & $0.053 * *$ & 3 \\
\hline Means & & & 910 & $\overline{5} . \overline{8} \overline{2} \pm$ & $\overline{3} . \overline{3} 0 \pm$ & $\overline{3} . \overline{0} \overline{1} \pm$ & & $\overline{0} . \overline{5} \overline{\overline{5}} \pm$ & $0 . \overline{6} \overline{3} \overline{8} \pm$ & 0.083 & 121 \\
\hline \multicolumn{12}{|c|}{ Commercial transboundary } \\
\hline Brazil & Alpine & ALP & 35 & $6.76 \pm$ & $4.08 \pm$ & $3.37 \pm$ & 1 & $0.674 \pm$ & $0.701 \pm$ & $0.040 *$ & 3 \\
\hline Brazil & Anglo-nubian & ANG & 41 & $5.826 \pm$ & $3.061 \pm$ & $\hat{2} . \hat{9} \hat{4} \pm$ & & $\hat{0.6004 ~} \pm$ & $\hat{0} . \hat{6} 400 \pm$ & $0.057 *$ & 2 \\
\hline Spain & Saanen & SAAN & 36 & $6.67 \pm$ & $\hat{3} . \hat{5} \overline{7} \pm$ & $\hat{3} . \overline{1} \overline{5} \pm$ & 2 & $0 \hat{0} \hat{2} \hat{4} \pm$ & $0.6 \overline{50} \pm$ & $0.041 *$ & 3 \\
\hline Means & & & 112 & $6 . \overline{4} \overline{3} \pm$ & $3 . \overline{5} \overline{5} \pm$ & 3..15 \pm & & $0 . \overline{3} \hat{4} \pm$ & $0 \hat{6} 6 \overline{6} \overline{4} \pm$ & 0.046 & 8 \\
\hline Overall & & & 1022 & $5 . \overline{8} 8 \pm$ & $\begin{array}{l}\hat{3} . \overline{3} 2 \pm \\
64\end{array}$ & $\begin{array}{l}\hat{3} .02 \\
34\end{array}$ & 17 & $\begin{array}{l}0.59 \overline{1} \pm \\
0.077\end{array}$ & $\begin{array}{c}0.6 \hat{4} 0 \overline{0} \\
074\end{array}$ & 0.083 & 129 \\
\hline
\end{tabular}

Breeds are grouped according to geographic area.

Abr., breed

$* P<0.05, * * P<0.01, * * * P<0.001$. 


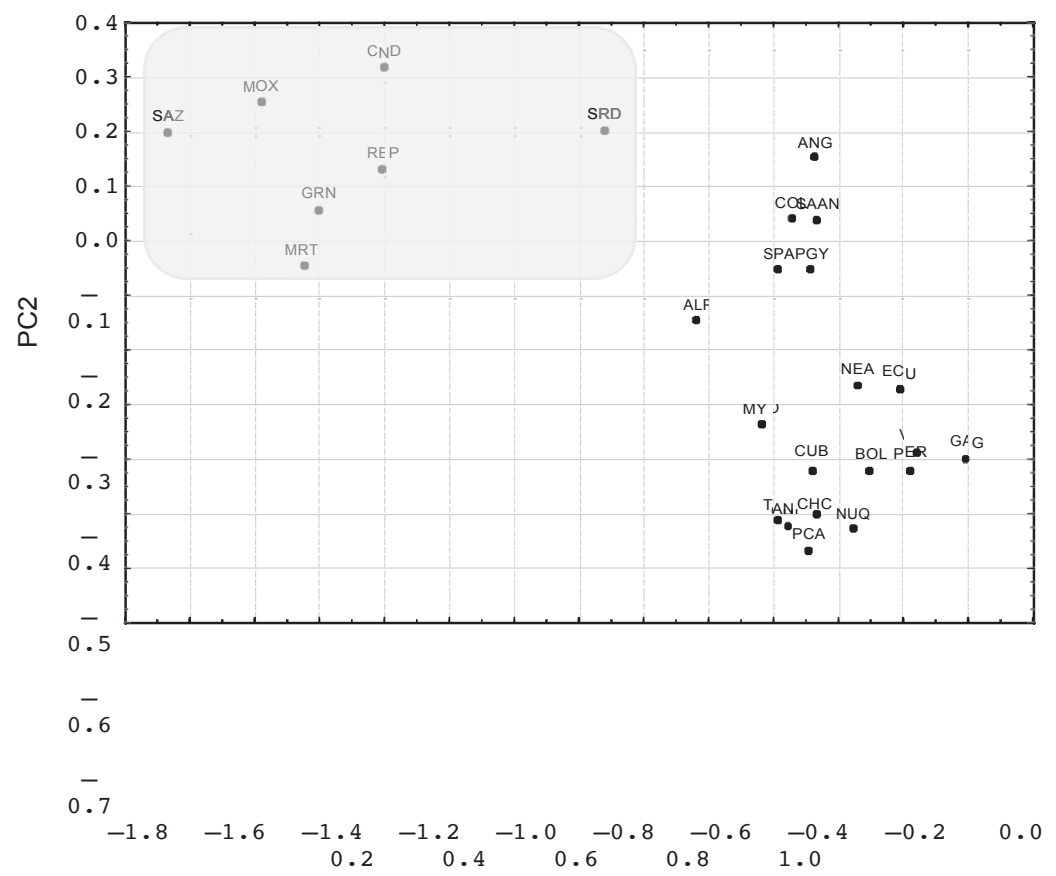

$\mathrm{PC} 1$

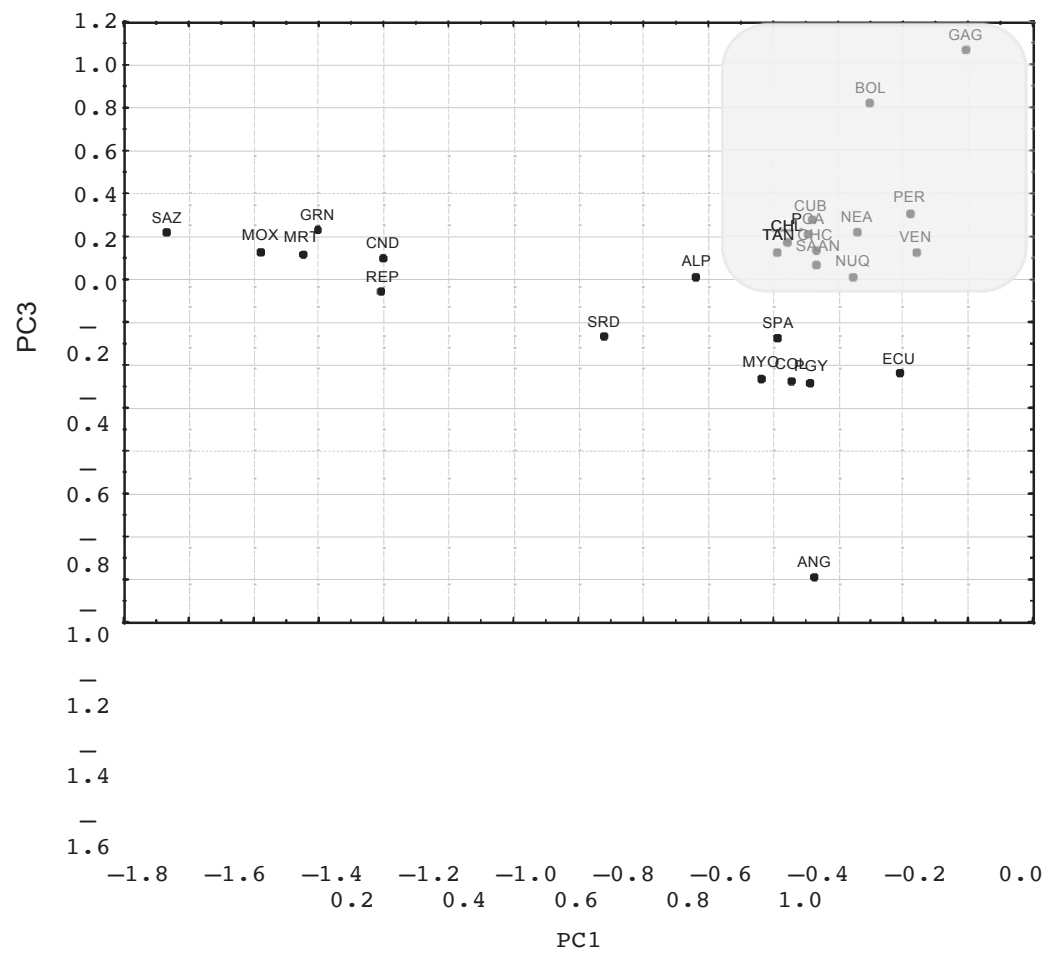

relationships among 24 Creole goat populations and three commercial transboundary goat breeds based on allele frequencies. Breed codes are def: in

Table 1. Shaded areas in gray depict groups of more closely related breeds. Axis 1: 25.15 \%

inertia, $\mathrm{P}=0.001$; Axis 2: $15.86 \%$ inertia,

$\mathrm{P}=0.001 ;$ Axis $3: 8.91 \%$ inertia, $\mathrm{P}=0.01$.

Figure 2 Analysis of principal

components graph depicting breed Animal Genetics, doi: 10.1111/age 12529 


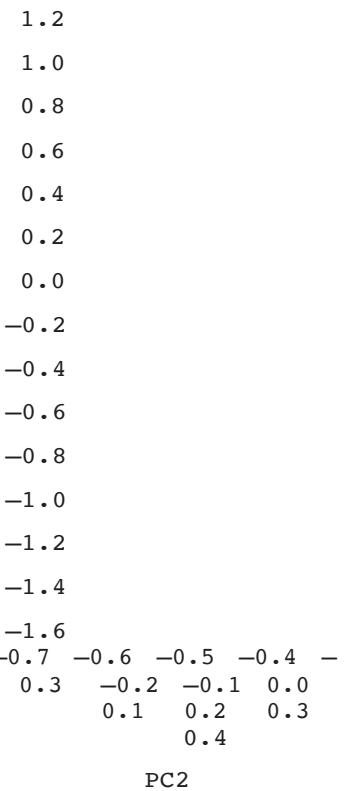

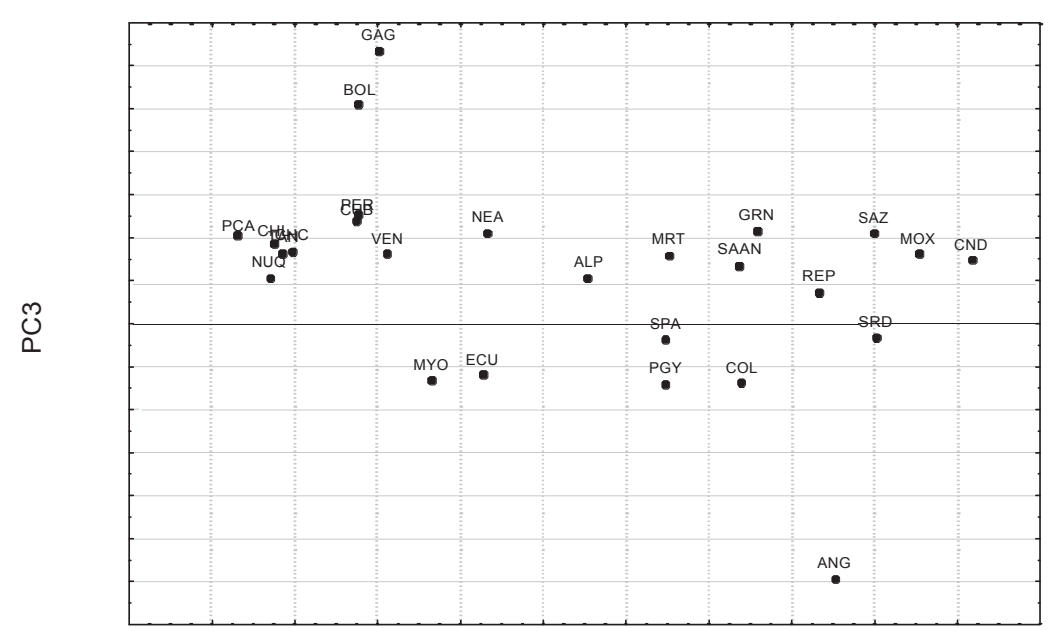

PC2 


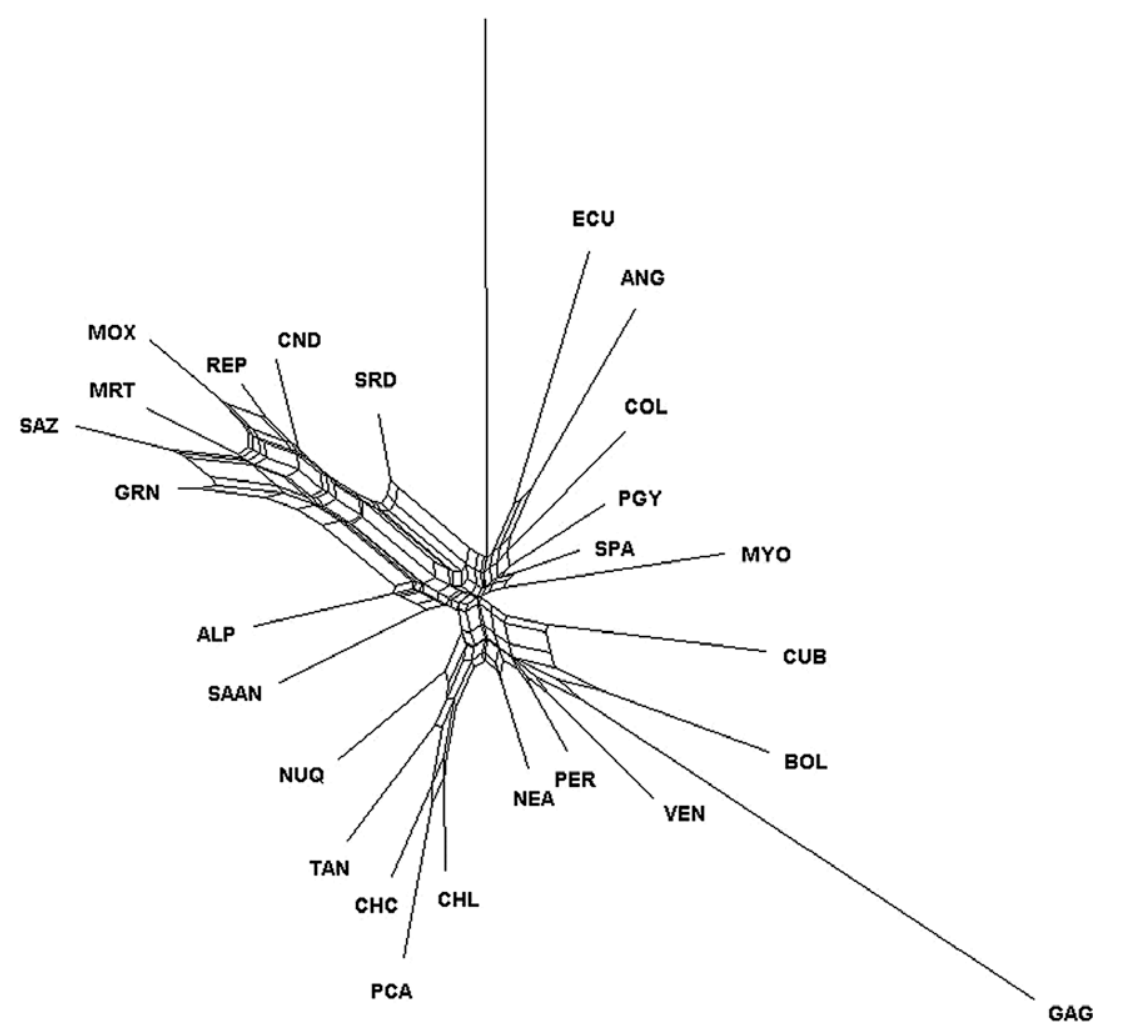

Figure 3 Neighbor-Net graph of $\mathrm{DA}$ genetic distances depicting breed relationships among 24 Creole goat populations and three com- mercial transboundary goat breeds.

based on axes 1 and 3 , they had a close genetic relationship with the Creole CUB, PER and VEN and the commercial Saanen goats (shaded area in gray) and split from MYO, SPA, COL, PGY and ECU.

The Neighbor-Net of DA genetic distances is shown in Fig. 3, and pairwise population distance values are shown in Table S2. The Brazilian goat breeds formed a tight net (supported by a high bootstrap value of $94 \%$; result not shown) and were somewhat genetically close to the transboundary ALP and SAAN breeds. The Argentinean Creole goats formed another breed group (bootstrap value of $75 \%$; result not shown) somewhat related to the PER, VEN, GAG, BOL and CUB. Criolla del Ecuador clustered with the commercial ANG breed and close to COL, PGY and SPA and, to a lesser extent, with the MYo breed. The San Clemente population split from the center as an independent and more distant branch.

Genetic structure and admixture analysis

For the STRUCTURE analysis done without including prior information on sample origin and following Evanno et al. (2005), the highest $\Delta \mathrm{K}$ values were found for $K=4(\Delta K=91.1)$ and $K=$ $21(\Delta \mathrm{K}=74.3)$ (Fig. $\mathrm{S} 1)$. The structure detected at $\mathrm{K}=4$ corresponds to the lowest variance of the likelihood of the data estimated over six independent runs, whereas the highest likelihood of the data was obtained for $\mathrm{K}=21$. The graphical representation of individual genotype membership coefficients (q) in each cluster is shown in Fig. 4. Based on individual $q$ values and at $K=4$, the Brazilian breeds grouped together (except for SRD, which showed influence of the commercial breeds, as expected), as did the Argentinean breeds, which were grouped with other more closely related Creole breeds (CUB, VEN, GAG, more closely related Creole breeds (CUB, VEN, GAG,
PER, BOL; Fig. 4a), in agreement with the results of the Neigh- bor-Net (Fig. 3). Influence of the commercial transboundary breeds in Creole goats could be inferred for SPA, MYO, COL, ECU and PGY, whereas the isolated SCL goat population formed an independent cluster. The breed groups at $\mathrm{K}=21$ (Fig. 4b, Table 2) indicate that most breeds formed inde- pendent clusters, whereas PGY split into two groups and the following breeds were grouped together: Brazilian SAZ and GRN; Brazilian MOX, CND and REP; Argentinean CHL, CHC, PCA and TAN; Ecuadorian ECU; and the North American SPA.

Further analyses were carried out with subsets of the data to determine if individuals of the Brazilian and Argentinean breed groups could be distinguished. The highest values of

$\Delta \mathrm{K}$ were obtained at $\mathrm{K}=3(\Delta \mathrm{K}=287.7)$ and $\mathrm{K}=5(\Delta \mathrm{K}=72.2)$ for the analysis of the Brazilian breeds SAZ, MOX, MRT, CND, REP and GRN (SRD was not included because it is a poorly defined and highly crossbred popu- lation). ALP was included as a reference breed for this analysis because it is a well-differentiated population and thus useful for determining the most probable $K$ value of this data subset. Based on individual $q$ values and at $K$ $=3$, 
goats

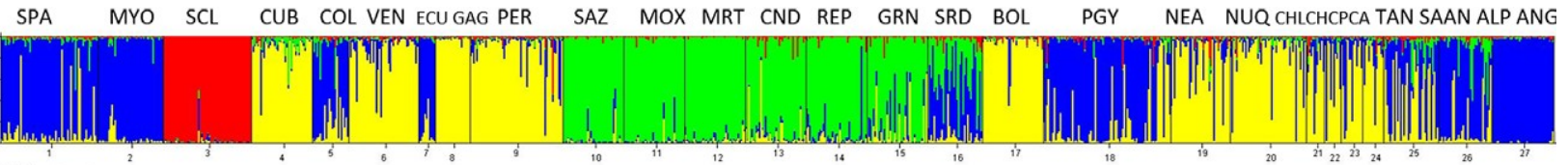

(a) $K=4$

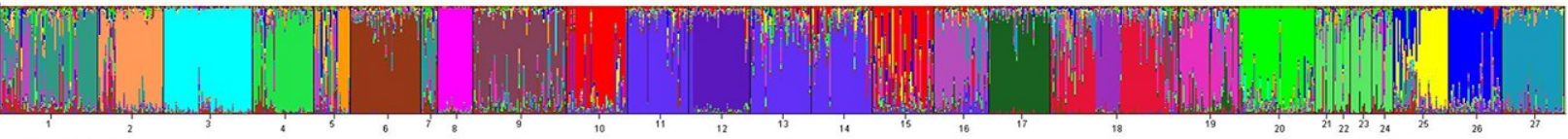

(b) $K=21$
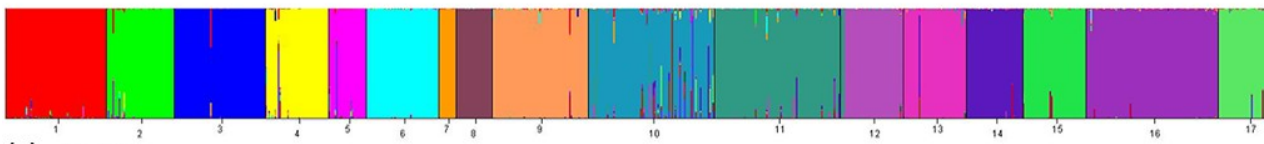

(c) $K=22$

Figure 4 Graphical representation of individual genotype membership coefficients (q) in each cluster obtained with STRUCTURE software without prior information on sample origin for $(\mathrm{a}) \mathrm{K}=4$ and $(\mathrm{b}) \mathrm{K}=21$ and (c) considering prior information on source breeds for $\mathrm{K}=22$.

the SAZ, MRT and GRN breeds formed one group; MOX, CND and REP another; and ALP an independent cluster (Fig. S2). At $\mathrm{K}=5$, MRT and CND formed independent clusters, whereas MOX and REP were in the same group as were SAZ and GRN. For the subset of Argentinean goats, the modal value of $\Delta \mathrm{K}=$ 129.8 was obtained at $\mathrm{K}=4$ with breeds NEA, NUQ and the reference ALP each in a separate cluster and CHL, CHC, PCA and TAN in the same group (Fig. S3).

The results of the Bayesian analysis carried out with STRUCTURE are summarized in Table 2, where the mean membership coefficients and percentages of animals assigned to each cluster are shown for scenarios without and with prior information on sample origin ( $\mathrm{K}=21$ or $\mathrm{K}=22$ respectively). When prior information on sample origin was ignored, and assuming $\mathrm{K}=21$, the average membership proportions in each cluster (Q) ranged from

$0.447 \pm 0.208$ in ECU to $0.937 \pm 0.0 .035$ in GAG with an overall average of $0.735 \pm 0.207$. Approximately $63 \%$ of the individuals were classified within their source cluster assuming a threshold of $q \geq 0.700$, whereas for more stringent threshold $q$ values, only $\sim 25 \%$ ( $q \geq$ $0.900), \sim 7 \%(\mathrm{~g} \geq 0.950)$ and $0 \%(\mathrm{~g} \geq 0.999)$ of the animals were correctly assigned (result not shown). There were several heterogeneous breeds (SPA, COL, ECU, PER, GRN, REP, CND, SRD, PGY, NEA, CHC and TAN) with less than $60 \%$ of the individuals assigned to their source cluster (for $q \geq$ 0.700 ) and/or over $30 \%$ of crossbred animals (i.e. with individual genotype membership q values < 0.700 but maximum in the source cluster). Also, the relatively high percentage of crossbred animals observed in the ALP breed ( $29 \%)$ appears to reflect the influence of this breed in some Brazilian Creole goats ( 10 ALP animals showed $q \geq$ $10 \%$ within the Brazilian breed group). Likewise, six ANG animals had $q \geq 10 \%$ in the SPA/ECU cluster (and the ECU breed had $\sim 13 \%$ of its mean genotype membership coefficient in the ANG cluster), which indicates some level of admixture between these breeds. For a threshold of $q \geq 0.700$, approximately $2 \%$ of the animals were misclas- sified to a cluster other than their source, with SAZ from Brazil showing $10 \%$ of the animals assigned to a different breed. The highest percentage of animals assigned to the source cluster $(100 \%$ with $q \geq 0.700)$ was observed in the GAG population, followed by six other breeds (SCL, VEN, MOX, MRT, BOL and PCA) with $>78 \%$ of individuals assigned for the same stringency threshold.

When prior information on source breeds was considered in the analysis (i.e. assuming the 22 breed clusters obtained in STRUCTURE without priors), the overall $\mathrm{Q}$ was $0.919 \pm 0.212$ and ranged from $0.605 \pm 0.464$ in GRN to $0.998 \pm$ 0.004 in GAG (Table 2). Individual $q$ values for $\mathrm{K}=$ 22 are depicted in Fig. 4c. The overall percentage of individuals assigned to the source cluster or breed was about $92 \%$ for $q \geq 0.700$ and $81 \%$ for $q \geq 0.950$, but this value fell considerably with the highest stringency $(\sim 17 \%$ with $q \geq$ $0.999)$. The percentage of animals assigned to the source cluster with $q \geq 0.950$ was greater than $70 \%$ in all breeds except GRN (50\%), REP (65\%) and CHL $(67 \%)$. Among the group of Creole goats analyzed, GAG (100\%), SCL (97\%), VEN (94\%), PCA $(93 \%), \operatorname{ECU}(91 \%)$ and MOX

$(90 \%)$ had the highest percentage of individuals assigned with $q \geq 0.950$. In fact, for the GAG and SCL populations, there were about $78 \%$ of animals with $q \geq 0.999$. Several of the animals that showed evidence of admixture were assigned to their source cluster $(q \geq 0.950)$ when prior information was considered. However, and particularly in the case of SAZ, REP, MRT and GRN, admixture was detected within the Brazilian breed group (including SRD goats) even when the source clusters were predefined. In the case of GRN, there were 14 individuals that showed ancestry across several source populations, including other Creole and commercial transboundary breeds (SAAN and ALP). 
Table 2 Summary results of the Bayesian cluster analysis done with STRUCTURE both with and without prior information on sample origin. Average genotype membership proportions (Q), the percentage of animals assigned to each cluster considering various threshold $q$ values, crossbred (Cross.) and misclassified (Miscl.) individuals at the lowest stringency (q values of 0.700 ) are shown for each breed and overall.

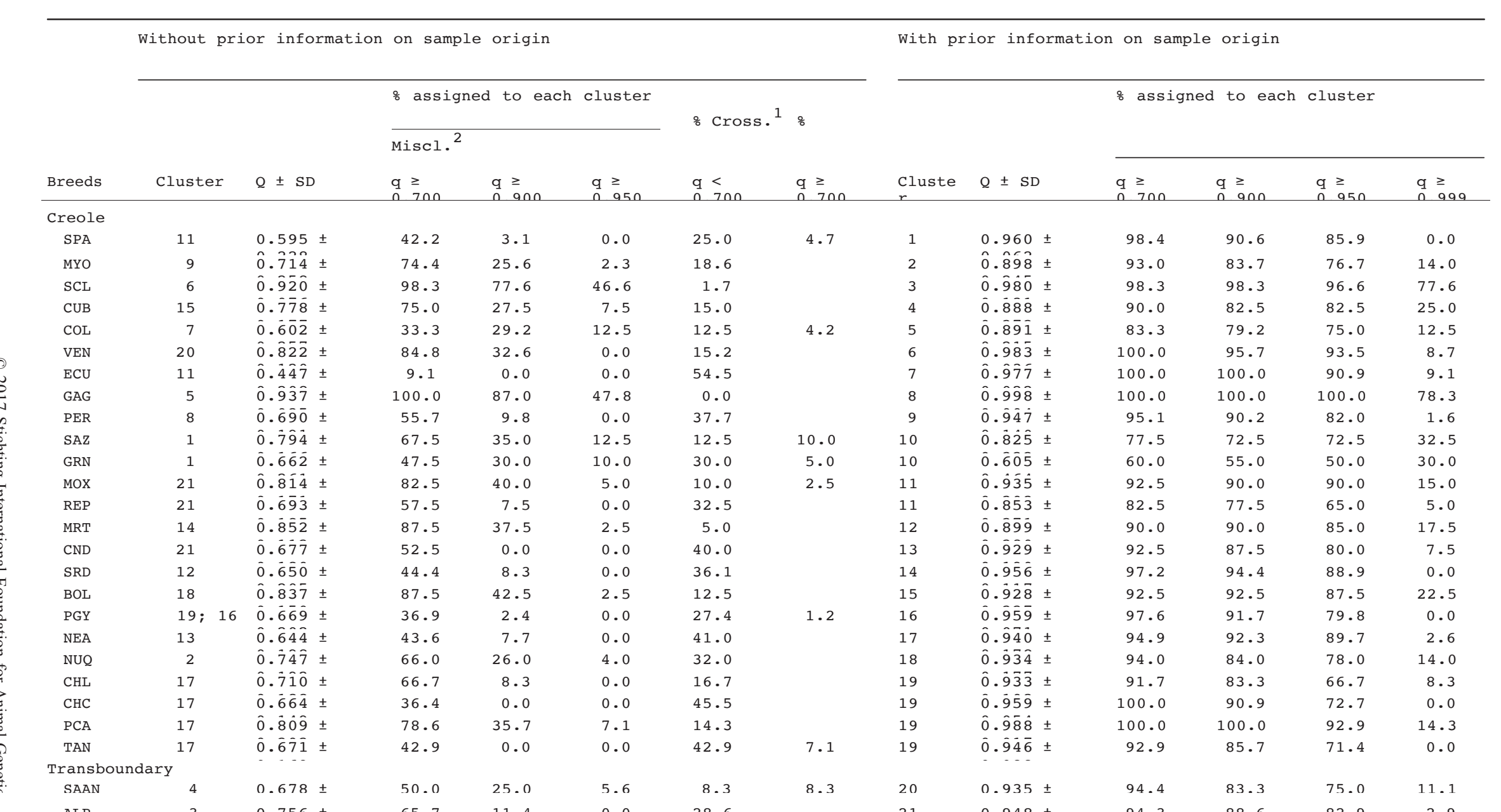


Discussion

This study covered a wide representation of goat genetic diversity in the Americas, and it represents the first comprehensive analysis of the five-century history of Creole goats. The microsatellite-based analysis adopted here accounts for the direct influence of genetic drift and migration in the evolution of Creole goat populations. Indirectly, it could also reflect the effects of natural and human selection in shaping the genetic composition of these local and well-adapted breeds. Our results depict the genetic diversity and population structure of 24 Creole goat populations from 10 countries and also the possible influence of three commercial transboundary breeds of worldwide distribution, which is relevant for the manage- ment and conservation of these important farm animal genetic resources. The genetic markers chosen follow FAO recommendations for genetic diversity studies, with a total number of alleles greater than four (except for ETH225, MAF209 and SPS115) and no null alleles detected at significant frequencies. The 21 STR markers used detected high levels of genetic diversity, with a total of 236 alleles observed across the 27 goat populations analyzed, and proved efficient for investigating the genetic relationships and population structure of Creole goats.

We observed an important level of within-breed genetic diversity in the creole goats tested (means for $\mathrm{H}_{\mathrm{O}}=0.585$ and $\mathrm{He}_{\mathrm{e}}=0.638$ ). Although it is difficult to make compar- isons with other studies that used different STR markers, the overall genetic diversity of Creole goats was analogous to that of their Central and North European counterparts $\left(\mathrm{H}_{\mathrm{O}}=0.594\right.$ and $\left.\mathrm{He}_{\mathrm{e}}=0.654\right)$ but lower than that estimated for East and Central Mediterranean goats $\left(\mathrm{H}_{\mathrm{O}}=0.663\right.$ and $\left.\mathrm{He}_{e}=0.737\right)$, as reported by Canon et al. (2006). When compared to the presumed ancestral goat breeds of the Iberian Peninsula $\left(\mathrm{H}_{\mathrm{O}}=0.610\right.$ and $\left.\mathrm{He}_{\mathrm{e}}=0.650\right)$, Creole populations show slightly lower levels of genetic diversity than do their Western European counterparts (Martinez et al. 2015). The somewhat low mean values of parameters assessing the overall diversity of Creole goats, particularly for allelic richness $\left(R_{t}=3.01\right)$ can be explained, in part, as the repercussion of the extremely low diversity found in breeds from San Clemente and Galapagos islands ( $\mathrm{Rt} \diamond 2.1$ and $\mathrm{H}_{\mathrm{O}} \diamond 0.400$ ), which is undoubtedly a consequence of genetic drift and inbreeding. But it can be expected that for other Creole breeds a strong founder effect and subsequent bottleneck events may have occurred, as few animals originating from the Iberian Peninsula reached the Antilles in the 15th century and had an exponential growth afterwards. Subsequent founder effects can probably be associated with the selection of some of these animals to colonize the continent in three directions (Primo 1992): to Veracruz (Mexico) and from there towards the north of the continent; to Panama and then towards Central America and the northern region of the Vice Kingdom of Peru; and from southern Peru towards R'10 de La Plata (although an alternative route of goat introduction in Patagonia by sea through Valdivia in Chile is considered; see Bandieri et al. 1993). Also, the Portuguese used the so-called capitanias to introduce goats in Brazil along the coast. Despite the heterogeneous origins of Creole goats, over time a few founder animals dispersed and were used to create new breeds well adapted to the distinct and often extreme environments of the Americas. Since the $19 \mathrm{th}$ century, the replacement of some Creole goat populations by trans- boundary commercial breeds, following model breeding programs developed in Europe, resulted in the current threatened status of many populations. This scenario can further explain the lower diversity detected here when compared to goats from other regions, such as the Middle East (Canon et al. 2006; Agha et al. 2008; Agaoglu \& Ertugrul 2012; Mahmoudi et al. 2014), Asia ( $\mathrm{Li}$ et al. 2002; Fatima et al. 2008; Dixit et al. 2012) and West Africa (Traor'e et al. 2009; Missohou et al. 2011). The few studies on Latin American goats reported similar overall values for the diversity parameters estimated in our study (Menezes et al. 2006; Oliveira et al. 2010; Calvo et al. 2012; Chacón et al. 2012; Ribeiro et al. 2012; Aranguren-M'endez et al. 2013). We observed that, for several Creole goat popula- tions, there was a large number of loci showing deviations from HWE (i.e. heterozygote deficit) along with significant $\mathrm{F}_{\text {is }}$ estimates (in some cases $>12 \%$ ) which can be due to inbreeding and/or within-breed substructure, i.e. a Wahlund effect (Hartl \& Clark 1997 ) associated with subdivided populations (for example, in some creole breeds it is common to find large isolated herds).

our results provide a broad perspective on the extant genetic diversity and population structure of Creole goats and to some extent can be interpreted as reflecting the mode of goat colonization in the Americas and the subsequent dilution resulting from crossbreeding with transboundary commercial breeds observed in a few Creole populations. We found some patterns of structure, with strong consistency between genetic distances among breeds and the Bayesian STRUCTURE analyses. For example, the Neighbor-Net graph showed a clear separation of the Brazilian and Argentinean breed groups relative to the remaining populations, which was supported by the clusters defined with STRUCTURE. The average Fst estimates also support a high level of breed differentiation among Creole goat populations, even when the highly divergent san Clemente and Galapagos island goats are excluded from the analyses, with an estimated $\mathrm{F}_{\mathrm{St}}=11 \%$, which is larger than the overall Fst value of $7 \%$ reported by Canon et al. (2006) for Northern European, Mediterranean and Middle Eastern goat breeds.

The observed level of genetic differentiation among goat populations from the various Latin American regions could possibly be associated with the two distinct colonization routes of the Spanish (Rodero et al. 1992) and the 
Portuguese conquerors (Primo 1992), and further studies

including Iberian breeds are essential to clarify thic acnort perspective, the yellow cluster STRUCTURE $\stackrel{\text { for }}{\text { for }} \mathrm{K}=4$ (supported by the highest $\Delta \mathrm{K}$ roluld represent the original Spanish grouping Cuban goats (as putative representatives of initially introduced in the Caribbean Islands) with grants from Venezuela, Galapagos, Peru,

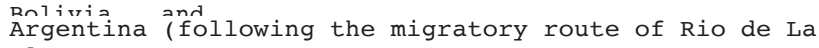
Dowards Patagonia). In Creole goats from Ecuador and Paraguay, the more recent influanra nf nhat of the Anglo-Nubian, which is a dairy goat breed hadapted to the tropics, and possibly diluting former cirns- of Iberian ancestry. Such influence was also in the SPA and MYO breeds of the USA within the nnrthorn
route of goat dispersion in the Americas. Creole Argentina can be separated in two breed groups by the northeastern (NEA) breed, and the central (PCA) southern breeds (CHL, $\mathrm{CHC}$ and NUQ). The NEA ic entangled with the creole goats from other neighbouring South American countries, such as Peru Bolivia, but also with the breeds from venezuela and Within the central-southern breed group, the PCA ifrmm thr with the creole Chilluda goats ( $\mathrm{CHL}$ and $\mathrm{CHC}$ )

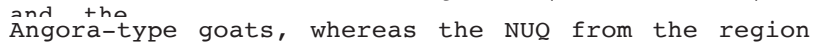
Patagonia formed an independent cluster, possibly of founder effects and genetic isolation. The mean Fst 'observed for the Argentinean breed group ( $\sim 4 \%$ ) suggests that $\mathrm{CHL}$ and $\mathrm{CHC}$ indeed represent the same

breed.

The differentiation of the Brazilian breeds, green in Fig. 4, may reflect their common origin from introduced in the 16 th century by the Portuguese in tho some level of genetic proximity only between the GRN CND breeds and their Portuguese counterparts. Yet, possible influence of goat populations from other namiñ from West Africa or Asia, cannot be theseriar could $\vec{\partial}^{c}$ also have reached the Americas ris +rata
routes. Indeed, the STRUCTURE analysis showed clear that GRN is a heterogeneous population, for which infl" its low percentage of individuals assigned. The analysis revealed three major breed groups in Roliows: the MOX breed, which is white or cream with hlegs and a black stripe on the back (a similar nat+arn $+\cdots+h o i r$
Portuguese counterpart serpentina), clustered rrith $D F D$
whose name refers to the split colour between the forequarters and brown, pale hind (or vice versa); the coloured MRT clustered with the CND breed, which is hith ${ }^{2}$ a white belly; and the black-coloured GRN, of Iberian ancestry (Ribeiro et al. 2012), clustered blue-coloured SAz goats, allegedly of West African origin but also with phenotypic patterns similar to that shown by

the Portuguese Serrana breed.

Despite the typical genetic heterogeneity goats, the assignment results obtained in our

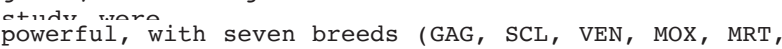
BOL and PCA) showing more than $78 \%$ of

individuslc their source cluster when the analyses prior information on sample origin ( $q \geq 0.700$ ). surprising that these corresponded to breeds or to those with a more organized hrandar'e. Nevertheless, and except for three (GRN, REP and CHL), all Creole breeds had over 70\% individuals assigned when a threshold $q$ value of adopted. These results indicate that most creole have their own identity, which supports these hroore oc management and conservation programs. rhacults also provide a first basis for the breed registries (i.e. herdbooks), which are still lorlinarin.

Our study consisted of a fine-scale analysis of structure of creole goats, but a more scrutiny of worldwide goats is needed to unveil the of Creole goats of the Americas and the multiple influonroc they have suffered, namely by including Wharian African populations along with other widely dicnorcold
commercial transboundary breeds.

Groeneveld et al. (2010) concluded in their review of farm animal diversity studies that ular analyses of autosomal and Y-chromosomal variation are necessary to reveal the evolutionary trajecto- ries of goats. Recently, high-density SNP arrays have been

developed for several livestock species, inclurinr rosser-klopp et al. 2014), and the genotyping dropped significantly, making it possible to carry analysis at the population level with a large nhese whole-genome markers as well as nextgenoratinn hinalyses in farm animals (Lenstra et al. 2012; Marsan et al. 2014) to investigate adaptation traits et al. 2015) and to disclose evolutionary signatures contribute to a better understanding of their histories. In goats, SNP arrays have been used for norantora (Talenti et al. 2016), to investigate and population structure (Nicoloso et al. 2015; Vici6) and to detect selection signatures 2016; Kim et al. 2016). However, whole-genome analysis in creole goats is still lacking.

This study is the first attempt towards a genetic characterization of American creole findings indicate that the observed levels of are not high when compared with breeds from other of the world, possibly as a consequence of creole farther away from the domestication center and ronrocant- ing the last stages of dispersal and evolution but founder effects related to the colonization process 
underlying their origin. In general, Creole breeds represent well-differentiated entities and require measures aimed at their conservation and sustainable utilization. Dilution from admixture with commercial transboundary breeds appears to be negligible in most Creole breeds, but the majority of them displays significant levels of inbreeding. The genetic relationships among creole breeds and the geographical patterns of genetic structure observed could reflect the effects of the alleged routes of expansion throughout the American continent during the colonization process, but a comprehensive study that includes goat breeds of Iberian and African origin is necessary to clarify the influence that breeds from these regions might have had in the develop- ment of Creole goats of the Americas.

\section{Acknowledgements}

The authors declare no conflict of interest. The authors wish to express thanks to breeder associations and research groups who kindly provided biological samples used in this study. Members of the CYTED XII-H and CONBIAND networks are thanked for valuable cooperation over the years. This study was partially supported by Instituto Nacional de Investigación y Tecnolog'ıa Agraria y Alimen- taria (INIA), spain (project references: RZ2004-00037-00-00, RZ2006-00005C02-00, RZ2007-00005-C02-01 and

RZ2007-00005-C02-02), and by the Brazilian Government through CNPq and CAPES. CG was supported by a contract grant from the Fundagao para a Ciência e a Tecnologia (IF/ 00866/2014), Portugal.

\section{References}

Agaoglu O.K. \& Ertugrul O. (2012) Assessment of genetic diversity, genetic relationship and bottleneck using microsatellites in some native Turkish goat breeds. Small Ruminant Research 105, 53-60. Agha S.H., Pilla F., Galal S., Shaat I., D'Andrea M., Reale S., Abdelsalam A.Z.A. \& Li M.H. (2008) Genetic diversity in Egyptian and Italian goat breeds measured with microsatellite polymor- phism. Journal of Animal Breeding and Genetics 125, 194-200.

Ajmone-Marsan P., Colli L., Han J.L. et al. (2014) The character- ization of goat genetic diversity: towards a genomic approach. Small Ruminant Research 121, 58-72.

Aranguren-M'endez J., Portillo-R'ıos M., Rincón X., Mart'ınez A., Dickson L. \& D'Aubeterre R. (2013) Diversidad gen'etica en la cabra criolla venezolana mediante análisis con microsatelites. Revista Cientifica FCV-LUZ XXIII, 238-44.

Bandieri S., Favaro O. \& Morinelli M. (1993) Historia de Neuqu'en. Ed. Plus Ultra, Buenos Aires.

Belkhir K., Borsa P., Chikhi L., Raufaste N. \& Bonhomme F. (1996- 2004) GENETIX: Logiciel sous Windows TM pour la G'en'etique des Populations. Laboratoire G'enome, Populations, Interactions, CNRS, Universit'e de Montpellier II, Montpellier, France.

Boettcher P.J., Hoffmann I., Baumung R. et al. (2014) Genetic resources and genomics for adaptation of livestock to climate change. Frontiers in Genetics 5, 461.
Bruford M.W., Ginja C., Hoffmann I. et al. (2015) Prospects and challenges for the conservation of farm animal genomic resources, 2015-2025. Frontiers in Genetics 6, 314.

Bruno-de-Sousa C., Martinez A.M., Ginja C., SantosSilva F., Carolino M.I., Delgado J.V. \& Gama L.T. (2011) Genetic diversity and population structure in Portuguese goat breeds. Livestock Science 135, 131-9.

Burren A., Neuditschko M., Signer-Hasler H., Frischknecht M., Reber I., Menzi F., Drogemuller C. \& Flury C. (2016) Genetic diversity analyses reveal first insights into breed-specific selection signatures within Swiss goat breeds. Animal Genetics

$$
47,727-39 \text {. }
$$

Calvo S.J., Gonzáles M.I., Á ngel P.A., Cerón-Munoz M.F. \& Cardona-

Cadavid H. (2012) Genetic evaluation of the goat population of Antioquia, using microsatellite markers. Livestock Research for Rural Development 24; Article \#82. Retrieved December 18 ,

2016, from

http://www.lrrd.org/lrrd24/5/gonz24082.htm Canon

J., Garc'ıa D., Garc'ıa-Atance M.A., Obexer-Ruff G., Lenstra

J.A., Ajmone-Marsan P. \& Dunner S. (2006) Geographical partitioning of goat diversity in Europe and the Middle East. Animal Genetics 37 , 327-34.

Chacón E., La O.M., Velásquez F.J., P'erez E., Delgado J.V., Cos Y., Fonseca Y. \& Mart'ınez A. (2012) Validation of the racial standards of the Cuban Creole goat for its international registration. REDVET - Revista Electr'onica de Veterinaria $13,1-8$.

Chapuis M.P. \& Estoup A. (2007) Microsatellite null alleles and estimation of population differentiation. Molecular Biology and Evolution $24,621-31$.

Delgado J.V., Martinez A.M., Acosta A. et al. (2012) Genetic characterization of Latin-American Creole cattle using microsatellite markers. Animal Genetics 43, 2-10.

Dempster A.P., Laird N.M. \& Rubin D.B. (1977) Maximum likelihood from incomplete data via the EM algorithm. Journal of the Royal Statistical Society, Series B, Statistical Methodology 39, 1-38.

Dixit S.P., Verma N.K., Aggarwal R.A.K., Vyas M.K., Rana J. \& Sharma A. (2012) Genetic diversity and relationship among Indian goat breeds based on microsatellite markers. Small Ruminant Research 105, 38-45.

Evanno G., Regnaut S. \& Goudet J. (2005) Detecting the number of clusters of individuals using the software STRUCTURE: a simulation study. Molecular Ecology 14, 2611-20.

Falush D., Stephens M. \& Pritchard J.K. (2003) Inference of population structure using multilocus genotype data: linked loci and correlated allele frequencies. Genetics 164, 1567-87.

FAO (2007) The State of the World's Animal Genetic Resources for Food and Agriculture (Ed. by B. Rischkowsky \& D. Pilling), p. 512. Food and Agriculture Organization of the United Nations, Rome, Italy.

Fatima S., Bhonga C.D., Ranka D.N. \& Joshi C.G. (2008) Genetic variability and bottleneck studies in Zalawadi, Gohilwadi and Surti goat breeds of Gujarat (India) using microsatellites. Small Ruminant Research 77, 58-64.

Ginja C., Penedo M.C., Melucci L., Quiroz J., Martinez Lopez O.R., Revidatti M.A., MartinezMartinez A., Delgado J.V. \& Gama L.T. (2010) Origins and genetic diversity of New World Creole cattle: inferences from mitochondrial and $Y$ chromosome polymor- phisms. Animal Genetics 41, 128-41.

Ginja C., Gama L.T., Cortes O. et al. (2013) Analysis of conservation priorities of Iberoamerican cattle based on autosomal microsatel- lite markers. Genetics Selection Evolution 45, 35. 
Goudet J. (1999) PCAGEN, Vers. 1.2. Institute of Ecology, University of Lausanne, Lausanne, Switzerland.

Goudet J. (2001) FSTAT: a program to estimate and test gene diversities and fixation indices. Journal of Heredity $86,485-6$.

Groeneveld L.F., Lenstra J.A., Eding H. et al. (2010) Genetic diversity in farm animals-a review. Animal Genetics 41(Suppl. 1), 6-31.

Guo S.W. \& Thompson E.A. (1992) Performing the exact test of Hardy-Weinberg proportion for multiple alleles. Biometrics 48, 361-72.

Hartl D.L. \& Clark A.G. (1997) Principles of Population Genetics. Sinauer Associates, Sunderland, MA, USA.

Hoffmann I. (2010) Climate change and the characterization, breeding and conservation of animal genetic resources. Animal Genetics $41,32-$ 6 .

Hoffmann I., Marsan P.A., Barker J.S.F., Cothran E.G., Hanotte O., Lenstra J.A., Milan D., Weigend S. \& Simianer H. (2004) New MoDAD Marker Sets to be Used in Diversity Studies for the Major Farm Animal Species: Recommendations of a Joint ISAG/FAO Working Group. FAO, Rome.

Huson D.H. \& Bryant D. (2006) Application of phylogenetic networks in evolutionary studies. Molecular Biology and Evolution 23, 254-67.

Iamartino D., Bruzzone A., Lanza A., Blasi M. \& Pilla F. (2005) Genetic diversity of southern Italian goat populations assessed by microsatellite markers. Small Ruminant Research $57,249-55$.

Kim S.C., Kang S.H., Choi E.Y., Hong Y.H., Bok J.D., Kim J.Y., Lee S.S., Choi Y.J., Choi I.S. \& Cho K.K. (2016) Cloning and characterization of an endoglucanase gene from Actinomyces sp. Korean native goat 40. Asian-Australas Journal of Animal Science 29, 126-33.

Langella O. (1999-2002) POPULATIONS 1.2.28.

CNRS UPR9034, France.

Lenstra J.A., Groeneveld L.F., Eding H. et al. (2012) Molecular tools and analytical approaches for the characterization of farm animal genetic diversity. Animal Genetics 43, 483-502.

Li M., Zhao S., Bian C. et al. (2002) Genetic relationships among twelve Chinese indigenous goat populations based on microsatel- lite analysis. Genetics Selection Evolution 34, 729-44.

Mahmoudi B., Panahi B., Mohammadi S.A., Daliri M. \&

Babayev

M.S. (2014) Microsatellite based phylogeny and bottleneck studies of Iranian indigenous goat populations. Animal Biotech- nology 25, 210-22.

Martinez A.M., Gama L.T., Delgado J.V. et al. (2015) The South- western fringe of Europe as an important reservoir of caprine biodiversity. Genetics Selection Evolution $47,86$.

Menezes M.P., Mart'ınez A.M., Ribeiro M.N., PimentaFilho E.C. \&

Bermejo J.V.D. (2006) Caracterizag்ão genética de raç as caprinas

nativas Brasileiras utilizando 27 marcadores microssaté lites.

Revista Brasileira de Zootecnia 35, 1336-41. Missohou A., Poutya M.R., Nenonene A., Dayo G.K., Ayssiwede S.B., Talaki E., Issa Y. \& Fane A.

(2011) Genetic diversity and differentiation in

nine West African local goat breeds assessed via microsatellite polymorphism. Small Ruminant Research 99, 20-4. Naderi S., Rezaei H.R., Pompanon F. et al. (2008) The goat domestication process inferred from large-scale mitochondrial DNA analysis of wild and domestic individuals. Proceedings of the National Academy of Sciences of 17659-64
Nei M., Tajima F. \& Tateno Y. (1983) Accuracy of estimated phylogenetic trees from molecular data. Journal of Molecular Evolution 19, 153-70.

Nicoloso L., Bomba L., Colli L. et al. (2015) Genetic diversity of Italian goat breeds assessed with a medium-density SNP chip. Genetics Selection Evolution 47, 62 .

oliveira J.C.V., Ribeiro M.N., Rocha L.L., GomesFilho M.A., Delgado J.V., Martinez A.M., Menezes M.P.C., Bettencourt C.M.

\& Gama L.T. (2010) Genetic relationships between two homol- ogous goat breeds from Portugal and Brazil assessed by microsatellite markers. Small Ruminant Research 93, 79-87.

Peakall R. \& Smouse P.E. (2006) GENALEX 6: genetic analysis in EXCEL: population genetic software for teaching and research. Molecular Ecology Notes 6 288-95.

Primo A.T. (1992) El ganado bovino Iberico en las Americas: 500 anos despues. Archivos Zootecnia $41,421-32$.

Pritchard J.K., Stephens M. \& Donnelly P. (2000) Inference of population structure using multilocus genotype data. Genetics 155, 945-59. Raymond M. \& Rousset F. (2003) GENEPOP (version 3.4). update of Raymond, M. \& Rousset, F. (1995) GENEPOP: population genetics software for exact tests and ecumenicism. Retrieved from http:// genepop.curtin.edu.au/

Revidatti M.A., Bermejo J.V.D., Gama L.T., Periati V.L., Ginja C., Alvarez L.A., Vega-Pla J.L. Martinez A.M. \& Consortium B. (2014) Genetic characterization of local Criollo pig breeds from the Americas using microsatellite markers. Journal of Animal Science 92, 4823-32.

Ribeiro M.N., Bruno-de-Sousa C., Martinez-Martinez A., Ginja C., Menezes M.P.C., Pimenta E.C. Delgado J.V. \& Gama L.T. (2012) Drift across the Atlantic: genetic differentiation and population structure in Brazilian and Portuguese native goat breeds. Journal of Animal Breeding and Genetics $129,79-87$

Rodero A., Delgado J.V. \& Rodero E. (1992) Primitive Andalusian livestock and their implications in the discovery of America. Archivos de Zootecnia $41,383-400$

Serrano M., Calvo J.H., Martinez M., MarcosCarcavilla A., Cuevas J., Gonzalez C., Jurado J.J. \& de Tejada P.D. (2009) Microsatellite based genetic diversity and population structure of the endan- gered Spanish Guadarrama goat breed. BMC Genetics 10,61 .

Sulabda N., Susari N.N.W., Heryani N.L.G.S. \& Puja I.K. (2012) Genetic diversity of Gembrong Goat based on DNA microsatellite markers. Indonesian Journal of Animal and Veterinary Science 17, 25-35.

Talenti A., Nicolazzi E.L., Chessa S. et al. (2016) A method for single nucleotide polymorphism selection for parentage assessment in goats. Journal of Dairy Science 99, 3646-53.

Tosser-Klopp G., Bardou P., Bouchez O. et al. (2014) Design and characterization of a $52 \mathrm{~K}$ SNP chip for goats. PLoS One 9, e86227.

Traor'e Á lvarez I., Tambourá H.H. et al. A., (2009) Genetic

characterisation of Burkina Faso goats using microsatellite polymorphism. Livestock Science $123,322-8$.

Villalobos Cort'es A.I., Mart'ınez A.M., Vega-Pla J.L. \& Delgado J.V. (2011) Genetic structure and bottleneck of the Guaymi bovine population by means of microsatellites. Archivos de zootecnia 60, 76775 .

Visser C., Lashmar S.F., Van Marle-Koster E., Poli M.A. \& Allain D. (2016) Genetic diversity and population structure in South African, French and Argentinian Angora Goats from genome- wide SNP data. PLOS ONE 11, e0154353. 
Walsh P.S., Metzger D.A. \& Higuchi R. (1991) Chelex 100 as a medium for simple extraction of DNA for PCR-based typing from forensic material. BioTechniques 10, 506-13.

Weir B.S. \& Cockerham C.C. (1984) Estimating Fstatistics for the analysis of population structure. Evolution 38, 1358-70.

Supporting information

Additional supporting information may be found online in the supporting information tab for this article:

Figure $\mathrm{S} 1$ Modal distribution of $\Delta \mathrm{K}$ values following

Evanno

et al. (2005) estimated for $\mathrm{K}=2$ to $\mathrm{K}=30$ for 24

Creole goat

populations and three commercial transboundary goat breeds.

Figure S2 Results of the substructure analysis of six Creole

goat breeds from Brazil and the commercial

transboundary

Alpine goat breed.
Figure S3 Results of the substructure analysis of six Creole goat breeds from Argentina and the commercial trans- boundary Alpine goat breed.

Table S1 Total number of alleles (TNA), mean number of alleles (MNA), effective number of number of alleles (MNA), effective number of
alleles $\left(\mathrm{n}_{\mathrm{e}}\right)$, allelic richness (Rt), populations showing private alleles (PA), observed ( $\left.\mathrm{H}_{\mathrm{O}}\right)$ and expected $(\mathrm{He})$ heterozygosities, Weir and Cockerham F Statistics (Fis, $F_{i t}$ and $F_{S t}$ ) and number of populations showing heterozygote deficit (HWEd) estimated for each STR locus in 24 Creole and 3 commercial

transboundary goat breeds.

Table S2 Pairwise-population (above diagonal) and DA Fst

(below diagonal) values.

genetic distances for and $D_{A}$

breed groups.

(c) 2017 Stichting International Foundation for Animal Genetics, doi: 10.1111/age.12529 